\title{
Obstructing Sleep Apnea in Pregnancy
}

\author{
Waseem Qureshi ${ }^{1,}$,, M. Ismail ${ }^{2}$, G. Hassan ${ }^{2}$ \\ ${ }^{1}$ Department of Chest Medicine, Government Medical College, Srinagar, India \\ ${ }^{2}$ Department of Medicine, Government Medical College, Srinagar, India
}

Email address:

qureshiwaseem786@gmail.com(W.Qureshi)

${ }^{*}$ Corresponding author

\section{To cite this article:}

Waseem Qureshi, M. Ismail, G. Hassan. Obstructing Sleep Apnea in Pregnancy. Journal of Anesthesiology. Vol. 6, No. 1, 2018 , pp. 6-9. doi: $10.11648 /$ j.ja.20180601.12

Received: January 24, 2018; Accepted: February 11, 2018; Published: April 3, 2018

\begin{abstract}
Background: Obstructive sleep apnea (OSA), the most important and treatable form of sleep disordered breathing is common in significant proportion of general population, and also in pregnant women. Method: our study including 1000 population based study and was question wear based. During the periods of apnea there is fall in oxygen saturation because of collapse of upper airways. In pregnant females, this process I.e. exaggerated by hormonal influence. Result: There is significant literature demonstrating adverse effects of maternal and fetal outcome, and, treatment of OSA has demonstrated remarkable improvement in the maternal and fetal well being. Conclusion: So keeping public health in view, the article emphasizes basic concepts addressing this issue and management strategies for better maternal and fetal outcome.
\end{abstract}

Keywords: Pregnancy, Sleep Apnea, Hypertension, Pre-eclampsia, Intrauterine Growth Retardation

\section{Introduction}

Sleep disordered breathing (SDB) includes snoring, upper airway resistance syndrome, respiratory effort related arousals, obstructive sleep apnea and hypopnea syndrome. These disorders represent continuum of SDB, with snoring at one end and obstructive sleep apnea (OSA) at the other [1]. SDB is overall an under-estimated entity with lot of associated clinical disorders of public health importance. To understand the forthcoming description one should have basic knowledge of the subject to know the spectrum of adverse consequences.

Obstructive sleep apnea - hypopnea syndrome is characterized by recurrent episodes of upper airway collapse, fall of posterior portion of tongue musculature, leading to initially partial obstruction to airflow called hypopnea. As per the latest American Academy of Sleep Medicine Scoring Manual published [1] in 2007, hypopnea is defined as a $\geq$ $30 \%$ reduction in airflow associated with $\geq 4 \%$ drop in baseline arterial oxygen saturation or, alternately, a $\geq 50 \%$ reduction in airflow associated with $\mathrm{a} \geq 3 \%$ desaturation or associated with arousal. Respiratory effort-related arousal (RERA) is the sequence of breaths lasting at least 10 seconds characterized by increasing respiratory effort leading to arousal from sleep that does not meet criteria of apnea or hypopnea. RERA's suggest the presence of upper airway resistance syndrome. The average number of apneas and hypopneas per hour of sleep is called apnea - hypopnea index (AHI) and the information is obtained from the overnight polysomnography (sleep study). OSA-hypopnea syndrome is diagnosed when a patient has clinical picture with an AHI $>5$ events per hour, and the AHI > 30 events/hour suggests very severe OSA. The usual symptoms of OSA include day time somnolence, morning headaches, non-refreshing sleep, impaired concentration, fatigue, personality changes and overall deteriorated quality of life. There are several comorbid illnesses associated with OSA like hypertension, variety of cardiovascular consequences including cardiac arrhythmias, myocardial infarction, and sudden cardiac death. There are several modalities of treatment including weight reduction, improving sleep hygiene, oral appliances, variety of surgical procedures in case of mechanical obstruction like tonsillectomy, radioablation of tongue and correction of craniofacial abnormalities. However, treatment with positive airway pressure is the gold standard of treatment [3-5]. Normal 
pregnancy is associated with changes in the sleep pattern and architecture starting in the first trimester, attributed to increased levels of female sex hormones (estrogen and progesterone) and to several physiological phenomenon that occur in pregnancy, and effect normal sleep-wake pattern (Table 1) like nausea, vomiting, increased urinary frequency, heart burn and discomfort caused by fetal movements [6-9].

\subsection{Prevalence of OSA in Pregnancy}

The overall prevalence of OSA is estimated to be $5 \%$ to $6 \%$ among the women of reproductive age, ${ }^{2}$ however, its exact prevalence in pregnant women is not known in view of lack of large sample studies addressing this issue. Sleep apnea during pregnancy was first reported by Joel-Cohen and Sohoenfeld in 1978, and until the turn of twentieth century, the literature about sleep disordered breathing during pregnancy consisted largely of case reports. [10, 11]. Many studies are questionnaire-based, [12, 13] including our study of 1000 population showing overall prevalence of $13.4 \%{ }^{14}$ Although snoring is the most common symptom of OSA, it is less specific than other symptoms like witnessed apneas, choking sensations and arousals during sleep [12, 15] and have main limitation of lacking of polysomnographic confirmation of sleep apnea. In future, large sample population studies with polysomnographic confirmation of OSA are expected to come, and overall prevalence figures may become more clear.

\subsection{Impact of Pregnancy on Sleep Apnea}

Obstructive sleep apnea (OSA) may develop in women with pregnancy itself as risk factor or may worsen the severity of pre-existing OSA with potential adverse maternal and fetal outcomes. [16]. Physiological changes of pregnancy including progressive weight gain and upward displacement of the diaphragm may predispose women to OSA. Estrogen and progesterone levels increase significantly during the course of pregnancy. Estrogen induces hyperemia, nasopharyngeal mucosal edema, and vasomotor rhinitis [17, 18] leading to narrowing of upper airways with increased resistance to airflow. Additionally, nasal obstruction, especially chronic nasal congestion is an independent risk factor for SDB in general adult population. [19]. Hence it is evident that upper airway congestion secondary to estrogenmediated mechanisms, allergies or physiologic hypervolemia of pregnancy may increase the risk of SDB in pregnant women. Reduced upper airway dimensions, which is a risk factor for SDB, has been demonstrated among women in the third trimester of pregnancy [20]. There is increased diaphragmatic effort leading to greater suction pressure at the level of upper airway that can potentiate upper airway collapse. Because of reduction of functional residual capacity, the caudal traction on trachea and pharynx exerted by lung inflation decreases, thereby enhancing collapsiability of the pharynx. In addition, there is increased small airway closure at lung volumes greater than functional residual capacity, especially in late pregnancy $[21,22]$. All of these changes can lead to a reduction in maternal oxygen reserves. Episodes of apnea and hypopnea coupled with low maternal oxygen reserves can increase the risk of maternal hypoxemia and compromised oxygen delivery to the fetus. Frequency of central apneas may also be augmented by the increased stage 1 of sleep and sleep fragmentation that happens in late pregnancy $[16,23]$.

\subsection{Sleep Disordered Breathing Related Adverse Pregnancy Outcomes}

There are several published reports indicating that snoring and SDB during pregnancy is associated with adverse maternal fetal outcomes including pregnancy induced hypertension and low birth weight babies. This relationship of complications is not well elucidate again, because of lack of large sample prospective studies addressing this issue. [7, 21]. Pregnancy causes anatomic, physiologic and endocrinologic changes including narrowing of upper respiratory tract, which increases risk of OSA or worsens pre-existing sleep apnea. [21, 24]. Postulation about the association of SDB with gestational hypertension is based on the fact that OSA is an independent risk factor for hypertension. In a study conducted by Franklin and co-workers involving 502 pregnant women, it was found that incidence of hypertension and fetal growth retardation was significantly higher in pregnant women with habitual snoring compared to non-snores. [13]. It has been speculated that intermittent maternal hypoxia induced by SDB could cause placental ischemia, triggering oxidative stress and endothelial activations [21, 25]. Repetitive episodes of obstructive respiratory events may lead to maternal hypoxemia and peripheral vasoconstriction resulting in maternal hypertension and reduced placental delivery to the fetus. These mechanisms suggest a relationship of sleep apnea with intrauterine growth retardation [16]. Most of the previous studies are limited by small size samples and absence of polysomnographic evidence of OSA resulting in inconsistent results. Recent evidence supports the role of endothelial dysfunction in the development of eclampsia. Studies have demonstrated reduced antioxidant capacity and increased lipid peroxidation - features of inflammatory activation that mediates vascular damage of placenta. Preeclampsia has been associated with increased activation of sympathetic system and increased risk of cardiovascular disease and worsening of cardiovascular complications of OSA [26, 27].

Prolonged intermittent maternal hypoxia during OSA causes fetal heart rate decelerations, decreased fetal breathing movements and eventually fetal growth retardation [28]. Intra-uterine growth retardation as a consequence of OSA has been demonstrated by several other studies as well [29, 30]. Apart from growth retardation and low birth weight, studies have demonstrated OSA in pregnancy associated with preterm birth, [31] small for gestational age, [32] cesarean section, [33] and low APGAR scores [34]. 


\section{Evaluation of OSA During Pregnancy}

The diagnosis of sleep disorders, especially OSA in pregnant women needs a sound sleep history including various questionnaires like Epworth Sleepiness Score and Berlin questionnaire. ${ }^{35}$ Pien and Schwab ${ }^{21}$ have proposed that pregnant women with excessive day time sleepiness, loud snoring and witnessed apneas should be evaluated for OSA with overnight polysomnography (strength of recommendation, C). The excessive day time sleepiness should not be explained by simple insufficient sleep caused by other stresses created by pregnancy. Santiago and coworkers [6] stressed that the indication for polysomnography in pregnant women should be expanded to include those women with hypertension, previous babies with unexplained intra-uterine growth restriction, hypersomnia or insomnia associated with snoring or obesity (strength of recommendation, C). Sleep studies among pregnant women can be performed in a manner similar to those performed among non-pregnant women, and there are several studies demonstrated successfully performed nocturnal polysomnograms in pregnant women without difficulty [36, 37].

\section{Treatment of OSA during Pregnancy}

Efforts to treat SDB/OSA are of paramount importance during pregnancy keeping in view the possible adverse effect on pregnancy outcome and fetal health. All pregnant women should follow conservative measures like avoidance of excessive weight gain, sleeping in lateral position and restraining use of sedatives and alcohol. Treatment guidelines for pregnant women with OSA are similar to that of general population because data in pregnant women are yet limited. ${ }^{24}$ Oral appliances are impractical during pregnancy in view of multiple sessions needed during a short period of time for optimization of therapy, however, it may be an option among patients who cannot tolerate continuous positive airway pressure (CPAP) device. CPAP is the standard treatment for OSA among general population (strength of recommendation, A) indicated for moderate (AHI, 15-30 events/hour) to severe (AHI $>30$ events/ hour) OSA among general population [38].

Pien and Schwab [39] have recommended that pregnant women with severe OSA (AHI > 30 events/hour), mild to moderate OSA (AHI, 5-30 events/ hour) with clinical symptoms, or, recurrent oxyhemoglobin desaturation $<90 \%$ should receive treatment (strength of recommendation, C). CPAP therapy has been shown to improve cardiac output while reducing total peripheral resistance in patients with pre-eclampsia [40]. No adverse events have been reported among pregnant women with OSA who were treated with nasal CPAP therapy. [30, 31, 41, 42]. In pregnant women with pre-existing OSA, symptom recurrence should be assessed, especially if there is excess weight gain or gestational hypertension, and a repeat polysomnogram or titration of CPAP pressure is indicated if insufficient treatment is suspected (strength of recommendation, C) [39].

\section{Postpartum Management}

Based on the expert opinion [39] (strength of recommendation, $\mathrm{C}$ ), the following recommendations need to be followed at present:

1) Postpartum withdrawal of CPAP therapy with follow up for symptom recurrence can be attempted in mild to moderate pregnancy associated sleep apnea. If symptoms recur, a repeat polysomnogram to assess the baseline AHI is indicated.

2) For severe pregnancy-associated sleep apneas, therapy should be continued and, when weight returns to 10 $15 \%$ of baseline, a repeat polysomnogram should be obtained to establish baseline AHI and any need for continued therapy.

3) Patients with pre-existing OSA can safely return to prepregnancy therapy when their weight returns to $10-15 \%$ of baseline with close follow up for symptom recurrence.

4) All women with gestational sleep apnea should be monitored closely for symptom recurrence in subsequent pregnancies.

\section{Future Recommendations}

Based upon the above mentioned factors, and several studies supporting the fact of occurrence of obstructive sleep apnea in pregnancy with potential of adverse fetal outcome, sleep evaluation should be made for all pregnant women in the interest of better maternal and fetal health.

Table 1. Sleep disturbances in pregnancy.

\begin{tabular}{ll}
\hline & 1) Increased sleep duration \\
2) Increased awakening \\
3) Insomnia \\
4) Arousals \\
5) Daytime sleepiness \\
6) Daily naps \\
1) Increased total sleep time (first trimester) \\
2) Decreased sleep efficiency \\
3) Decreased stage 3 and $4\left(\mathrm{~N}_{3}\right)$ of non-REM sleep \\
4) Increased stage 1 of non-REM sleep \\
5) Increased wake time after sleep onset \\
6) Decreased total sleep time (third trimester)
\end{tabular}

\section{References}

[1] Tregear S, Reston J, Schrelles K, Philips B. Obstructive sleep apnea and risk of motor vehicle crash: systematic review and meta-analysis. J Clin Sleep Med 2009; 5(6): 573-581.

[2] The AASM manual for the scoring of sleep and associated events: rules, terminology and technical specifications, Westchester (IL): American Academy of Sleep Medicine: $2007,1^{\text {st }}$ edition.

[3] Sen MK, Suri JC. Cardiovascular consequences of obstructive sleep apnea. Indian J Sleep Med 2013; 8: 16-21.

[4] Dempsey JA, Veasey SC, Morgan BJ, O'Donnell CP. Pathophysiology of sleep apnea. Physiol Rev 2010; 90: 47112. 
[5] Guilleminault C, Quera-Salva MA, Partinen M, Jamieson A. Women and the obstructive sleep apnea syndrome. Chest 1998; 93: 104-113.

[6] Santiago JR, Nolledo MS, Kinzler W, et al. Sleep and sleep disorders in pregnancy. Ann Intern Med 2001; 134: 396-408.

[7] Edwards N, Middleton PG, Blyton DM, Sullivan CE. Sleep disordered breathing and pregnancy. Thorax 2002; 57: 555563.

[8] Schweiger MS. Sleep disturbances in pregnancy: a subjective survey. Am J Obstet Gynecol 1972; 114: 879-882.

[9] Young T, Palta M, Dempsey J, Skatrud J, Weber S, Badr S. The occurrence of sleep disordered breathing among middleaged adults. $N$ Engl J Med 1993; 328: 1230-1235.

[10] Joel-Cohen ST, Schoenfeld A. Fetal response to periodic sleep apnea: a new syndrome in obstetrics. Eur J Obstet Gynecol Reprod Biol 1978; 8: 77-81.

[11] Charbonneau M, Falcone T, Casio MG, Levy RD. Obstructive sleep apnea during pregnancy: therapy and implications of fetal health. Am Rev Respir Dis 1991; 144: 461-463.

[12] Pien GW, Fife D, Pack AI, Nkwuo JE, Schwab RJ. Changes in symptoms of sleep-disordered breathing during pregnancy. Sleep 2005; 28: 1299-1305.

[13] Franklin KA, Holmgren PA, Jonsson F, Poromaa N, Stenlund $\mathrm{H}$, Svanborg E. Snoring, pregnancy-induced hypertension and growth retardation of the fetus. Chest 2000; 117: 137-141.

[14] Ismail M, Raj Kumar, T Masood, G Hassan et al. Obstructive sleep apnea during pregnancy. Kashmir Medical Journal (In Press).

[15] Crocker BD, Olson LG, Saunders NA et al. Estimation of the probability of disturbed breathing during sleep before a sleep study. Am Rev Respir Dis 1990; 142: 14-21.

[16] Kapsimalis F, Kryger M. Obstructive sleep apnea in pregnancy. Sleep Med Clin 2007; 2: 603-613.

[17] Elkus R, Ropovich J Jr. Respiratory physiology in pregnancy. Clin Chest Med 1992; 13: 555-565.

[18] Mabry RL. Rhinitis of pregnancy. South Med J 1986; 79: $965-$ 971.

[19] Young T, Finn L, Palta M. Chronic nasal congestion at night is a risk factor for snoring in a population-based cohort study. Arch Intern Med 2001; 161: 1514-1522.

[20] Izci B, Vennelle M, Liston WA, Dundas KC, Calder AA, Douglas NJ. Sleep disordered breathing and upper airway size in pregnancy and postpartum. Eur Respir J 2006; 27: 321-327.

[21] Pien GW, Schwab RJ. Sleep disorders in pregnancy. Sleep 2004; 27(7): 1405-1417.

[22] Bevan DR, Holderoft A, Loh L, MacGregor WG, O'Sullivan JC, Sykes MK. Closing volume and pregnancy. $\mathrm{Br}$ Med $\mathrm{J}$ 1974; 1: 13-20.

[23] Hertz G, Fast A, Feinsilver SH, Albertario CL, Schulman H, Fein AM. Sleep in normal late pregnancy. Sleep 1992; 15: 246-251.

[24] Venkata C, Venkateshiah SB. Sleep-disordered breathing during pregnancy. J Am Board Fam Med 2009; 22: 158-168.
[25] Yinon D, Lowenstein L, Surya S, et al. Pre-eclampsia is associated with sleep-disordered breathing and endothelial dysfunction. Eur Respir J 2006; 27: 328-333.

[26] Dekker GA, Sibai BM. Etiology and pathogenesis of preeclampsia: current concepts. Am J Obstet Gynecol 1998; 179: 1359-1375.

[27] Rodie VA, Freeman DJ, Sattar N, et al. Pre-eclampsia and cardiovascular disease: metabolic syndrome of pregnancy. Atherosclerosis 2004; 175: 189-202.

[28] Ritchie K. The fetal response to changes in the composition of maternal inspired air in human pregnancy. Semin Perinatol 1980; 4: 295-299.

[29] Charbonneau M, Falcone T, Cosio MG, et al. Obstructive sleep apnea in pregnancy: therapy and implications. Am Rev Respir Dis 1991; 144: 461-463.

[30] Lefcourt LA, Rodis JF. Obstructive sleep apnea in pregnancy. Obstet Gynecol Surv 1996; 51(8): 503-509.

[31] Kapsimalis F, Kryger M. Sleep breathing disorders in US female population. J Womens Health 2009; 18: 1211-1219.

[32] Roush SF, Bell L. Obstructive sleep apnea in pregnancy. $J$ Am Board Fam Pract 2004; 17: 292-296.

[33] Louis JM, Auckley D, Sokol RJ, Mercer BM. Maternal and neonatal morbidities associated with obstructive sleep apnea complicating pregnancy. Am J Obstet Gynecol 2010; 202: 261. e1-5.

[34] Champagne KA, Kimoff RJ, Barriga PC, Schwartzman K. Sleep disordered breathing in women of childbearing age and during pregnancy. Indian J Med Res 2010; 131: 285-301.

[35] Facco FL, Kremer J, Ho KH, Zee PC, Grobman WA. Sleep disturbances in pregnancy. Obstet Gynecol 2010; 115(1): 7783.

[36] Guilleminault C, Kreutzer M, Chang JL. Pregnancy: sleepdisordered breathing and treatment with nasal continuous positive airway pressure. Sleep Med 2004; 5: 43-51.

[37] Sahin FK, Foken G, Cosar E, et al. Obstructive sleep apnea in pregnancy and fetal outcome. Int J Gynecol Obstet 2008; 100: 141-146.

[38] Kushida CA, Littner MR, Hirshkowitz M, et al. Practice parameters for the use of continuous and bi-level positive airway pressure devices to treat adult patients with sleeprelated breathing disorders. Sleep 2006; 29: 375-380.

[39] Pien GW, Schwab RJ. Sleep disorders during pregnancy. Sleep 2004; 27: 1405-1417.

[40] Blyton DM, Sullivan CE, Edwards N. Reduced nocturnal cardiac output associated with pre-eclampsia is minimized with the use of nocturnal CPAP. Sleep 2004; 27: 79-84.

[41] Kowall J, Clark G, Nino-Murcia G, Powell N. Precipitation of obstructive sleep apnea during pregnancy. Obstet Gynecol 1989; 74: 453-458.

[42] Brain KA, Thornton JG, Sarkar A, Johnson AO. Obstructive sleep apnea and fetal death: successful treatment with continuous positive airway pressure. $\mathrm{Br} J$ Obstet Gynecol 2001; 108: 543-547. 